DOI: https://doi.org/10.47405/mjssh.v5i6.655

\begin{tabular}{|c|c|}
\hline 4 & Malaysian Journal of Social Sciences and Humanities (MJSSH) \\
\hline $\begin{array}{l}\text { Malaysian Juoural of } \\
\text { Social ccciecces and }\end{array}$ & Volume 5, Issue 6, June 2020 \\
\hline (MJ-sSH) & e-ISSN : 2504-8562 \\
\hline & $\begin{array}{l}\text { Journal home page: } \\
\text { www.msocialsciences.com }\end{array}$ \\
\hline
\end{tabular}

\title{
Persepsi Guru terhadap Penggunaan Whatsapp Messenger dalam Pengajaran Sejarah
}

\author{
M. Kaviza ${ }^{1}$ \\ ${ }_{1}^{1}$ Pusat Pengajian Pendidikan dan Bahasa Moden, Universiti Utara Malaysia (UUM) \\ Correspondence: M. Kaviza (kavizakaviza@yahoo.com)
}

\begin{abstract}
Abstrak
Kajian ini bertujuan untuk mengenal pasti tahap persepsi guru terhadap penggunaan WhatsApp Messenger dalam pengajaran sejarah berdasarkan demografi guru. Seramai 39 orang guru terlibat dalam kajian ini. Instrumen kajian ini merupakan soal selidik. Data kajian ini telah dianalisis secara statistik deskriptif dan inferensi dengan menggunakan perisian IBM SPSS. Dapatan kajian ini telah menunjukkan bahawa tahap persepsi guru terhadap penggunaan WhatsApp Messenger dalam pengajaran sejarah berada pada tahap tinggi berdasarkan demografi guru iaitu jantina, opsyen, pengalaman mengajar dan kelulusan pendidikan walaupun dapatan kajian juga telah melaporkan bahawa tidak terdapat perbezaan min yang signifikan bagi persepsi penggunaan WhatsApp Messenger dalam pengajaran sejarah berdasarkan demografi guru. Kajian ini memberikan implikasi kepada pada guru sejarah untuk melaksanakan proses pengajaran dan pembelajaran sejarah dengan penggunaan WhatsApp Messenger.
\end{abstract}

Kata kunci: WhatsApp Messenger, pengajaran sejarah, persepsi, guru

\section{Teachers Perception of the Use of WhatsApp Messenger in Teaching History}

\begin{abstract}
This study aims to identify the level of teachers' perceptions of the use of WhatsApp Messenger in the teaching of history based on teacher demographics. A total of 39 teachers were involved in this study. The data of this study were analyzed descriptively and inferentially using IBM SPSS software. The findings of this study have shown that the level of teachers' perceptions of the use of WhatsApp Messenger in the teaching of history is at a high level based on the teacher demographics, namely gender, options, teaching experience and educational qualifications even though the findings have also shown that there is no significant mean difference in the perception of the use of WhatsApp Messenger in teaching history based on teacher demographics. This study has implications for history teachers to implement the process of teaching and learning history with the use of WhatsApp Messenger.
\end{abstract}

Keywords: WhatsApp Messenger, teaching of history, perception, teachers 


\section{Pengenalan}

Perkembangan teknologi mudah alih sejak kebelakangan ini telah menyebabkan penggunaan WhatsApp Messenger sebagai aplikasi alat rangkaian sosial menjadi semakin popular dalam proses pengajaran dan pembelajaran melalui penggunaan telefon pintar yang berperanan sebagai alat pesanan segera (Zulhanif \& Roslinda, 2019; Sonia \& Alka, 2017). Penggunaan WhatsApp Messenger dalam proses pengajaran dan pembelajaran telah membolehkan guru-guru dan murid-murid dapat menghantar pelbagai mesej yang berbentuk teks, imej, video, mesej audio dan sebagainya sama ada secara peribadi mahupun secara berkumpulan dengan kadar segera melalui kemudahan jaringan internet (Said, 2015; Izyani \& Mohamed Amin, 2016), di samping dapat membentuk proses komunikasi yang berkesan dan media literasi digital (Normazini, Alawiyah \& Wawarah, 2018; Muhammad Wildan \& Prarasta, 2019; Mwakapina, Mhandeni \& Nyinondi, 2016). Sehubungan dengan itu, adalah tidak disangkal bahawa murid-murid telah dilaporkan memaparkan persepsi yang baik terhadap penggunaan WhatsApp Messenger dalam proses pembelajaran mereka yang merentasi pelbagai bidang ilmu (Normah, Nor Azhan \& Mariam Mat, 2017; Zulhanif \& Roslinda, 2019; Ranjan, Jain \& Baghel, 2017). Namun, terdapat satu keperluan kepada pengkaji dalam kajian ini untuk meninjau persepsi guru-guru terhadap penggunaan WhatsApp Messenger dalam proses pengajaran, khususnya dalam mata pelajaran sejarah. Perkara ini perlu dikaji rentetan daripada dapatan kajian Tuan Sharifah, Mohd Mahzan dan Abdul Razaq (2019) yang telah memperincikan hubungan antara penggunaan aplikasi Telegram sebagai platform pembelajaran sejarah dan pencapaian murid dan dapatan kajian Kaviza (2020) dan kajian Fitriningas, Umamah dan Sumardi (2018) yang telah melaporkan tentang kesediaan murid dan potensi penggunaan aplikasi Google Classroom sebagai platform pembelajaran sejarah. Hal ini demikian kerana guru merupakan tunjang dalam merancang, mereka bentuk dan melaksanakan aktiviti pembelajaran yang bermakna di dalam kelas melalui pengintegrasian aplikasi WhatsApp Messenger dengan efektif (Niveen, 2016). Maka, kajian ini adalah bertujuan untuk mengenal pasti tahap persepsi guru terhadap penggunaan WhatsApp Messenger dalam pengajaran sejarah berdasarkan demografi guru iaitu jantina, opsyen, pengalaman mengajar dan kelulusan pendidikan.

\section{Objektif Kajian}

Objektif kajian ini ialah:

i. Mengenal pasti tahap persepsi guru terhadap penggunaan WhatsApp Messenger.

ii. Mengenal pasti tahap persepsi guru terhadap penggunaan WhatsApp Messenger berdasarkan demografi guru iaitu jantina, opsyen, pengalaman mengajar dan kelulusan Pendidikan.

iii. Mengenal Pendidikan ada terdapat perbezaan min yang signifikan bagi persepsi terhadap penggunaan WhatsApp Messenger berdasarkan demografi guru iaitu jantina, opsyen, pengalaman mengajar dan kelulusan Pendidikan.

\section{Persoalan Kajian}

Persoalan kajian ini ialah:

i. Apakah tahap persepsi guru terhadap penggunaan WhatsApp Messenger?

ii. Apakah tahap persepsi guru terhadap penggunaan WhatsApp Messenger berdasarkan demografi guru iaitu jantina, opsyen, pengalaman mengajar dan kelulusan pendidikan?

iii. Adakah terdapat perbezaan min yang signifikan bagi persepsi terhadap penggunaan WhatsApp Messenger berdasarkan demografi guru iaitu jantina, opsyen, pengalaman mengajar dan kelulusan pendidikan? 


\section{Hipotesis Kajian}

Bagi menjawab soalan kajian 3, maka empat hipotesis kajian telah dibentuk untuk diuji pada tahap kesignifikan $p=0.05$ iaitu:

$\mathrm{H}_{\mathrm{ol}}$ : Tidak terdapat perbezaan min yang signifikan bagi persepsi terhadap penggunaan WhatsApp Messenger berdasarkan jantina.

$\mathrm{H}_{\mathrm{o} 2}$ : Tidak terdapat perbezaan min yang signifikan bagi persepsi terhadap penggunaan WhatsApp Messenger berdasarkan opsyen.

$\mathrm{H}_{03}$ : Tidak terdapat perbezaan min yang signifikan bagi persepsi terhadap penggunaan WhatsApp Messenger berdasarkan pengalaman mengajar.

$\mathrm{H}_{04}$ : Tidak terdapat perbezaan min yang signifikan bagi persepsi terhadap penggunaan WhatsApp Messenger berdasarkan kelulusan pendidikan.

\section{Metod Kajian}

Kajian berbentuk tinjauan ini melibatkan seramai 39 orang guru. Instrumen kajian ini merupakan soal selidik likert lima mata dan mempunyai nilai Cronbach alpha iaitu 0.91 yang dianggap baik dan diterima bagi tujuan kajian ini (Nunnally \& Bernstein, 1994) Data kajian ini dianalisis secara statistik deskriptif dan inferensi iaitu ujian-t bagi sampel tak bersandar dan ujian ANOVA Satu Hala dengan menggunakan perisian IBM SPSS. Tahap interpretasi persepsi dalam kajian ini telah ditentukan berdasarkan tiga tahap interpretasi skor min yang diadaptasi daripada kajian Jamil (2002) seperti ditunjukkan pada Jadual 1.

Jadual 1: Interpretasi Skor Min dan Tahap

\begin{tabular}{ll}
\hline Skor Min & Tahap \\
\hline $1.00-2.33$ & Rendah \\
$2.34-3.66$ & Sederhana \\
$3.67-5.00$ & Tinggi \\
\hline
\end{tabular}

Sumber: Adaptasi daripada Jamil (2002)

\section{Dapatan Kajian}

\section{Tahap Persepsi Guru Terhadap Penggunaan WhatsApp Messenger}

Berdasarkan Jadual 2, tahap persepsi guru terhadap penggunaan WhatsApp Messenger $(M=3.99$, $S D=0.52$ ) adalah berada pada tahap tinggi. Justeru, dapat dirumuskan bahawa tahap persepsi guru terhadap penggunaan WhatsApp Messenger dalam pengajaran sejarah adalah berada pada tahap tinggi dalam kajian ini.

Jadual 2: Persepsi Terhadap Penggunaan WhatsApp Messenger

\begin{tabular}{llll}
\hline & Min $(\boldsymbol{M})$ & $\begin{array}{l}\text { Sisihan Piawai } \\
(\boldsymbol{S D})\end{array}$ & Tahap \\
\hline Persepsi & 3.99 & 0.52 & Tinggi \\
\hline
\end{tabular}


DOI: https://doi.org/10.47405/mjssh.v5i6.655

\section{Tahap Persepsi Terhadap Penggunaan WhatsApp Messenger Berdasarkan Demografi Guru}

\section{Tahap Persepsi Terhadap Penggunaan Whatsapp Messenger Berdasarkan Jantina}

Berdasarkan Jadual 3, tahap persepsi terhadap penggunaan WhatsApp Messenger adalah berada pada tahap tinggi dalam kalangan guru lelaki dan guru perempuan. Selain itu, min persepsi terhadap penggunaan WhatsApp Messenger bagi guru lelaki adalah lebih tinggi $(M=4.06, S D=0.35)$ berbanding dengan guru perempuan $(M=4.32, S D=0.50)$. Justeru, dapat dirumuskan bahawa tahap persepsi terhadap penggunaan WhatsApp Messenger dalam pengajaran sejarah adalah berada pada tahap tinggi dalam kalangan guru lelaki dan guru perempuan dalam kajian ini.

Jadual 3: Tahap Persepsi Terhadap Penggunaan WhatsApp Messenger Berdasarkan Jantina

\begin{tabular}{lllll}
\hline Jantina & $\mathbf{N}$ & $\begin{array}{l}\text { Min } \\
(\boldsymbol{M})\end{array}$ & Sisihan Piawai $(\boldsymbol{S D})$ & Tahap \\
\hline Lelaki & 14 & 4.06 & 0.35 & Tinggi \\
Perempuan & 25 & 3.96 & 0.60 & Tinggi \\
\hline
\end{tabular}

\section{Tahap Persepsi Terhadap Penggunaan WhatsApp Messenger Berdasarkan Opsyen}

Berdasarkan Jadual 4, tahap persepsi terhadap penggunaan WhatsApp Messenger adalah berada pada tahap tinggi dalam kalangan guru opsyen sejarah dan guru bukan opsyen sejarah. Selain itu, min persepsi terhadap penggunaan WhatsApp Messenger adalah lebih tinggi $(M=4.04, S D=0.61)$ bagi guru bukan opsyen sejarah berbanding dengan guru opsyen sejarah $(M=3.98, S D=0.50)$. Justeru, dapat dirumuskan bahawa tahap persepsi terhadap penggunaan WhatsApp Messenger dalam pengajaran sejarah adalah berada pada tahap tinggi bagi guru opsyen sejarah dan guru bukan opsyen sejarah dalam kajian ini.

Jadual 4: Tahap Persepsi Terhadap Penggunaan WhatsApp Messenger Berdasarkan Opsyen

\begin{tabular}{lllll}
\hline Jantina & N & Min $(\boldsymbol{M})$ & Sisihan Piawai $(S D)$ & Tahap \\
\hline Opsyen Sejarah & 31 & 3.98 & 0.50 & Tinggi \\
Opsyen Bukan sejarah & 8 & 4.04 & 0.61 & Tinggi \\
\hline
\end{tabular}

\section{Tahap Persepsi Terhadap Penggunaan WhatsApp Messenger Berdasarkan Pengalaman Mengajar}

Berdasarkan Jadual 5, tahap persepsi terhadap penggunaan WhatsApp Messenger adalah berada pada tahap tinggi berdasarkan pengalaman mengajar dalam kalangan guru. Selain itu, min persepsi terhadap penggunaan i WhatsApp Messenger adalah lebih tinggi bagi guru yang berpengalaman antara 6 hingga 10 tahun $(M=4.42, S D=0.51)$ berbanding dengan guru yang berpengalaman antara 1 hingga 5 tahun $(M=4.04, S D=0.56), 11$ hingga 15 tahun $(M=3.77, S D=0.93)$ dan 16 tahun ke atas $(M=3.92, S D=0.44)$. Justeru, dapat dirumuskan bahawa tahap persepsi terhadap penggunaan WhatsApp Messenger dalam pengajaran sejarah adalah tinggi berdasarkan pengalaman mengajar dalam kalangan guru dalam kajian ini.

Jadual 5: Statistik deskriptif bagi Persepsi Penggunaan WhatsApp Messenger Berdasarkan Pengalaman Mengajar

\begin{tabular}{lllll}
\hline Pengalaman Mengajar & N & Min $(\boldsymbol{M})$ & $\begin{array}{l}\text { Sisihan } \\
\text { Piawai }(S D)\end{array}$ & Tahap \\
\hline 1-5 tahun & 7 & 4.04 & 0.56 & Tinggi \\
6-10 tahun & 5 & 4.42 & 0.51 & Tinggi \\
11-15 tahun & 3 & 3.77 & 0.93 & Tinggi \\
\hline
\end{tabular}


DOI: https://doi.org/10.47405/mjssh.v5i6.655

\begin{tabular}{lllll}
\hline 16 tahun ke atas & 24 & 3.92 & 0.44 & Tinggi \\
\hline
\end{tabular}

\section{Tahap Persepsi Terhadap Penggunaan WhatsApp Messenger Berdasarkan Kelulusan Pendidikan}

Berdasarkan Jadual 6, tahap persepsi terhadap penggunaan WhatsApp Messenger adalah berada pada tahap tinggi berdasarkan kelulusan pendidikan dalam kalangan guru. Selain itu, min persepsi terhadap penggunaan WhatsApp Messenger adalah lebih tinggi bagi guru yang berkelulusan ijazah sarjana $(M=4.40, S D=0.57)$ berbanding dengan guru yang berkelulusan diploma $(M=4.10, S D=0.71)$ dan berkelulusan ijazah sarjana muda $(M=3.97, S D=0.52)$. Justeru, dapat dirumuskan bahawa tahap persepsi terhadap penggunaan WhatsApp Messenger dalam pengajaran sejarah adalah tinggi berdasarkan kelulusan pendidikan dalam kalangan guru dalam kajian ini.

Jadual 6: Statistik deskriptif bagi Persepsi Terhadap Penggunaan WhatsApp Messenger Berdasarkan Kelulusan Pendidikan

\begin{tabular}{lllll}
\hline Pengalaman Mengajar & N & Min $(\boldsymbol{M})$ & $\begin{array}{l}\text { Sisihan } \\
\text { Piawai }(\boldsymbol{S D})\end{array}$ & Tahap \\
\hline Diploma & 2 & 4.10 & 0.71 & Tinggi \\
Ijazah Sarjana Muda & 35 & 3.97 & 0.52 & Tinggi \\
Ijazah Sarjana & 2 & 4.40 & 0.57 & Tinggi \\
\hline
\end{tabular}

\section{Perbezaan Min bagi Persepsi Terhadap Penggunaan WhatsApp Messenger Berdasarkan Demografi Guru}

\section{Perbezaan Min bagi Persepsi Terhadap Penggunaan WhatsApp Messenger Berdasarkan Jantina}

Berdasarkan keputusan ujian Levene's yang tidak signifikan $[F=4.85, p=0.34]$ pada Jadual 7 telah menunjukkan bahawa tidak terdapat perbezaan min yang signifikan bagi persepsi terhadap penggunaan WhatsApp Messenger $[t(35)=0.56, p=0.58]$ berdasarkan jantina. Maka, hipotesis nol $\left(\mathrm{H}_{\mathrm{ol}}\right)$ telah gagal ditolak. Justeru, dapat dirumuskan bahawa jantina tidak mempengaruhi persepsi terhadap penggunaan WhatsApp Messenger dalam pengajaran sejarah dalam kalangan guru dalam kajian ini.

Jadual 7: Ujian-t Sampel Tak Bersandar Bagi Min Persepsi Terhadap Penggunaan WhatsApp Messenger Berdasarkan Jantina

\begin{tabular}{|c|c|c|c|c|c|c|c|c|c|}
\hline & & & \multicolumn{7}{|c|}{ Ujian-t bagi persamaan min } \\
\hline & \multicolumn{2}{|c|}{$\begin{array}{l}\text { Ujian } \\
\text { Levene's }\end{array}$} & \multirow[t]{2}{*}{$t$} & \multirow[t]{2}{*}{$d f$} & \multirow[t]{2}{*}{$p$} & \multirow[t]{2}{*}{$\begin{array}{l}\text { Perbezaan } \\
\text { min }\end{array}$} & \multirow[t]{2}{*}{$\begin{array}{l}\text { Min } \\
\text { ralat } \\
\text { Piawai }\end{array}$} & \multicolumn{2}{|c|}{$\begin{array}{l}99 \% \text { selang } \\
\text { keyakinan bagi } \\
\text { perbezaan }\end{array}$} \\
\hline & $F$ & Sig & & & & & & Bawah & Atas \\
\hline $\begin{array}{l}\text { Perbezaan } \\
\text { Min }\end{array}$ & 4.85 & 0.34 & 0.56 & 37 & 0.58 & 0.10 & 0.17 & -0.26 & 0.45 \\
\hline
\end{tabular}

\section{Perbezaan Min bagi Persepsi Terhadap Penggunaan WhatsApp Messenger Berdasarkan Opsyen}

Berdasarkan keputusan ujian Levene's yang tidak signifikan $[F=1.11, p=0.30]$ pada Jadual 8 telah menunjukkan bahawa tidak terdapat perbezaan min yang signifikan bagi persepsi terhadap penggunaan WhatsApp Messenger $[t(35)=-0.26, p=0.80]$ berdasarkan opsyen. Maka, hipotesis nol $\left(\mathrm{H}_{\mathrm{o} 2}\right)$ telah gagal ditolak. Justeru, dapat dirumuskan bahawa opsyen tidak mempengaruhi persepsi terhadap penggunaan WhatsApp dalam pengajaran sejarah dalam kalangan guru dalam kajian ini. 
DOI: https://doi.org/10.47405/mjssh.v5i6.655

Jadual 8: Ujian-t Sampel Tak Bersandar Bagi Min Persepsi Terhadap Penggunaan WhatsApp Messenger Berdasarkan Opsyen

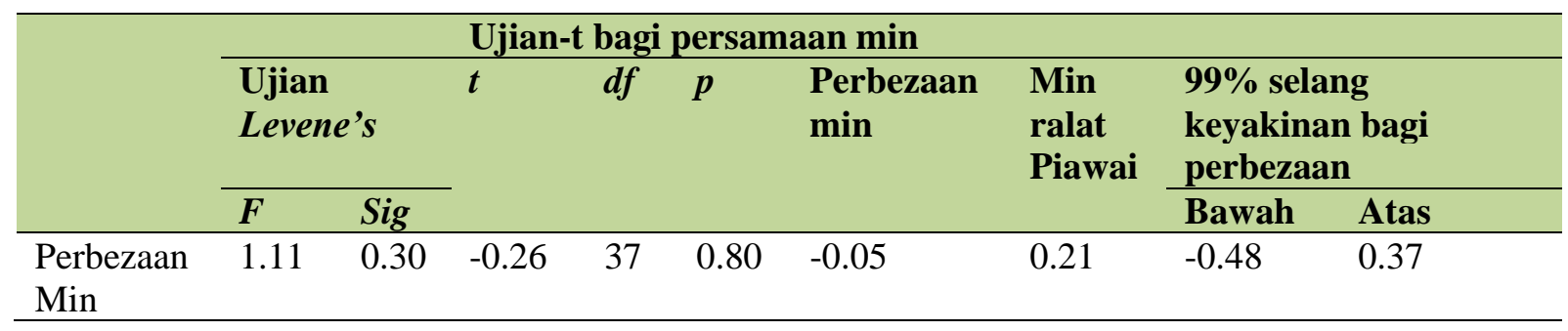

\section{Perbezaan Min bagi Persepsi Terhadap Penggunaan Whatsapp Messenger Berdasarkan Pengalaman Mengajar}

Berdasarkan keputusan ujian Levene's yang tidak signifikan $(F(1,35)=1.60, p=0.21)$, keputusan ujian ANOVA Satu Hala dalam Jadual 9 telah melaporkan bahawa tidak terdapat perbezaan min yang signifikan bagi persepsi terhadap penggunaan WhatsApp Messenger $[F(3,35)=1.56, p=0.22]$ berdasarkan pengalaman mengajar. Justeru, hipotesis nol $\left(\mathrm{H}_{03}\right)$ telah gagal ditolak. Justeru, dapat dirumuskan bahawa pengalaman mengajar tidak mempengaruhi persepsi terhadap penggunaan WhatsApp Messenger dalam pengajaran sejarah dalam kalangan guru dalam kajian ini.

Jadual 9: Keputusan Ujian ANOVA Satu Hala bagi Min Persepsi Terhadap Penggunaan WhatsApp Messenger Berdasarkan Pengalaman Mengajar

\begin{tabular}{lllllll}
\hline & $\begin{array}{l}\text { Jumlah } \\
\text { kuasa Dua }\end{array}$ & df & $\begin{array}{l}\text { Min Kuasa } \\
\text { Dua }\end{array}$ & $\boldsymbol{F}$ & Sig. \\
\hline Persepsi & Antara Kumpulan & 1.21 & 3 & 0.40 & 1.56 & 0.22 \\
& Dalam Kumpulan & 9.03 & 35 & 0.26 & & \\
& Jumlah & 10.24 & 38 & & & \\
\hline
\end{tabular}

Pada aras kesignifikan 0.05

\section{Perbezaan Min bagi Persepsi Terhadap Penggunaan WhatsApp Messenger Berdasarkan Kelulusan Pendidikan}

Berdasarkan keputusan ujian Levene's yang tidak signifikan $(F(2,36)=0.10, p=0.91)$, keputusan ujian ANOVA Satu Hala dalam Jadual 10 telah melaporkan bahawa tidak terdapat perbezaan min yang signifikan bagi persepsi terhadap penggunaan WhatsApp Messenger $[F(2,36)=0.69, p=0.51]$ berdasarkan kelulusan pendidikan. Justeru, hipotesis nol $\left(\mathrm{H}_{04}\right)$ telah gagal ditolak. Justeru, dapat dirumuskan bahawa kelulusan pendidikan tidak mempengaruhi persepsi terhadap penggunaan WhatsApp Messenger dalam pengajaran sejarah dalam kalangan guru dalam kajian ini.

Jadual 10: Keputusan Ujian ANOVA Satu Hala bagi Min Persepsi Terhadap Penggunaan WhatsApp Messenger Berdasarkan Kelulusan Pendidikan

\begin{tabular}{lllllll}
\hline & $\begin{array}{l}\text { Jumlah } \\
\text { kuasa Dua }\end{array}$ & df & $\begin{array}{l}\text { Min Kuasa } \\
\text { Dua }\end{array}$ & $\boldsymbol{F}$ & Sig. \\
\hline Persepsi & Antara Kumpulan & 0.38 & 2 & 0.19 & 0.69 & 0.51 \\
& Dalam Kumpulan & 9.86 & 36 & 0.27 & & \\
Jumlah & 10.24 & 38 & & & \\
\hline
\end{tabular}

Pada aras kesignifikan 0.05 


\section{Perbincangan Kajian}

Dapatan kajian ini yang menunjukkan bahawa tahap persepsi guru terhadap penggunaan WhatsApp Messenger dalam pengajaran sejarah yang tinggi berdasarkan ciri-ciri demografi guru iaitu jantina, opsyen, pengalaman mengajar dan kelulusan pendidikan walaupun tidak terdapat perbezaan min yang signifikan bagi persepsi penggunaan WhatsApp Messenger dalam pengajaran sejarah berdasarkan demografi guru adalah konsisten dengan dapatan kajian Aliff dan Mohd Isa (2013) yang telah melaporkan bahawa penerimaan guru Pendidikan Islam terhadap penggunaan telefon bimbit sebagai m-Pembelajaran adalah berada pada tahap tinggi, di samping dapatan kajian Ibtehal dan Faruzi (2013) yang telah melaporkan bahawa guru-guru mengakui potensi penggunaan WhatsApp Messenger sebagai alat interaksi komunikasi dan pertukaran idea dan maklumat. Sungguhpun begitu, dapatan kajian Jayalaxmi dan Kabelo (2016) yang turut menjelaskan potensi penggunaan WhatsApp Messenger dalam pembelajaran Matematik melalui reka bentuk 110 buah modul berdasarkan Theory Activity secara tidak langsung telah menyokong dapatan kajian ini. Hal ini demikian kerana WhatsApp Messenger merupakan aplikasi dalam telefon pintar yang dapat membentuk proses pengajaran dan pembelajaran yang menyeronokkan yang berupaya untuk menarik minat murid dalam proses pembelajaran (Boyindbode, Agbonito \& Ogundane, 2017; Bouhnik \& Deshen, 2014; Rambe \& Chipunza, 2013; Zulhanif \& Roslinda, 2019).

\section{Kesimpulan}

Kesimpulannya, dapatan kajian ini telah menunjukkan bahawa tahap persepsi guru terhadap penggunaan WhatsApp Messenger dalam pengajaran sejarah adalah tinggi berdasarkan ciri-ciri demografi guru iaitu jantina, opsyen, pengalaman mengajar dan kelulusan pendidikan. Implikasi kajian ini telah menyediakan sumber rujukan kepada para guru-guru sejarah untuk mengintegrasikan penggunaan WhatsApp Messenger dalam menjana proses pengajaran dan pembelajaran yang lebih menarik dan menyeronokkan serta meningkatkan kualiti pembelajaran melalui penerapan elemen teknologi maklumat dan komunikasi (Pusat Perkembangan Kurikulum, 2018; Kementerian Pendidikan Malaysia, 2013).

\section{Rujukan}

Aliff Nawi \& Mohd Isa Hamzah. (2013). Tahap Penerimaan penggunaan telefon bimbit sebagai mpembelajaran dalam Pendidikan Islam. Journal of Islamic and Arabic Education, 5(1), 1-10.

Bouhnik, D \& Deshen, M. (2014). Whatsapps goes to school: Mobile Instant messaging between teaching and students. Journal of Information Technology Education Research, 13, 217-231.

Boyinbode, O.K., Agbonito, O.C \& Ogundane, A. (2017). Supporting mobile learning with Whatsapps based on media richness. Circulation in computers Sciences, 2(3), 37-46.

Ibtehal, M.A \&Faruzi, F.I. (2013). The impact of Whatsapps on interaction in an Arabic language teaching course. International Journal of Arts \& Science, 6(3), 165-180.

Izyani Mistar \& Mohamed Amin Embi. (2016). Students perceptions on the use of whatsapps as learning tool in ESL Classroom. Journal of Education and Social Sciences, 4, 96-104.

Fitriningtiyas, D.A., Umamah \& Sumardi. (2018). Google Classroom: as a media of learning history. ICEGE: IOP Conferences Series Earth and Environmental Sciences, 243, 1-8.

Jayalaxmi, N \& Kabelo, J.K. (2016). Exploring the use of WhatsApp in Mathematic Learning: A case study. Journal of Communication, 7(2), 266-273.

Kaviza, M. (2020). Kesediaan murid terhadap penggunaan aplikasi Google Classroom sebagai platform pembelajaran sejarah. Malaysian Journal Social Sciences and Humanities, 5(4), 108115.

Kementerian Pendidikan Malaysia. (2013). Pelan Pembangunan Pendidikan Malaysia 2013-2025. Putrajaya: Kementerian Pendidikan Malaysia.

Muhammad Wildan Sahidillah \& Prarasta Miftahurrisqi (2019). Whatsapp sebagai media literasi digital siswa. Varia Pendidikan, 31(1), 52-57. 
Mwakapina, J.W., Mhandeni, A.S \& Nyinondi, O.S. (2016). Whatsapp mobile tool in second language learning: opportunitiess, potential and challenges in higher education settings in Tanzania. International Journal of Language Education, 4(2), 70-90.

Niveen, M.Z. (2016). Special Designed activities for learning English Language through the application of Whatsapps. English Language Teaching, 9(2), 199-204

Normah Husin, Nor Azhan Nurul Azmi \& Mariam Mat Daud (2017). Pembelajaran Kolaboratif melalui aplikasi telefon pintar dalam pembelajaran nahu. e-Jurnal Penyelidikan dan Inovasi, 4(1), 45-65.

Normazaini Saleh, Alawiyah tengah \& Wawarah Saidpudin (2018). Penggunaan Whatsapp sebagai alat komunikasi formal dalam organisasi: Satu tinjauan awal. Proceedings of the $5^{\text {th }}$ International Conference on management and Muamalah, 44- 56.

Pusat Perkembangan Kurikulum. (2013). Dokumen Standard Kurikulum dan Pentaksiran Sejarah Tingkatan 4 dan 5. Putrajaya: Kementerian Pendidikan Malaysia.

Rambe, P. \& Chipunza, C. (2013). Using mobile devices to leverage student access to collaborativelygenerated resources: A case of WhatsApp instant messaging at a South African University. Proceedings of the 2013 International Conferences on Advanced ICT.

Ranjan, R., Jain, A. \& Baghle, A.S. (2017). Whatsapps-assited learning of anatomy as an adjuvant to traditional class-room learning: achievement and prospect. International Journal of Anatomy and Research, 5(1), 3659-3664.

Said, F.E-S.A.F. (2015). The effectiveness of using whatsapps messenger as one of mobile learning techniques to developed students writing skills. Journal of Education and Practice, 6(32), 115127.

Sonia, G \& Alka, R. (2017). Effectivity of E-learning through Whatsapp as a teaching learning tol. MVP Journal of Medical Science, 4(1), 19-25.

Tuan Sharifah Khairiah Tuan Kechil, Mohd Mahzan Awang \& Abdul Razaq Ahmad. (2019). The relationship between telegram application as a history learning platform and student performance. Social Sciences, Education and Humanities, 2, 156-159.

Zulhanif Idris \& Roslinda Rosli. (2019). Whatsapp: Penggunaannya dalam membantu pembelajaran matematik tambahan dalam kalangan pelajar sekolah menengah tahfiz kerajaan di Kuala Lumpur. e-Prosiding Persidangan Antarabangsa Sains Sosial dan Kemanusiaan, 73-92. 